\title{
Sociodemographic factors responsible for blindness in diabetic Egyptian patients
}

This article was published in the following Dove Press journal:

Clinical Ophthalmology

4 November 2011

Number of times this article has been viewed

Khaled Gamal Ibraheem

Abueleinen'

Hany El-Mekawey'

Yasser Sayed Saif ${ }^{2}$

Amr Khafagy'

Hoda Ibrahim Rizk ${ }^{3}$

Eman M Eltahlawy ${ }^{4}$

'Department of Ophthalmology,

Cairo University, Cairo, Egypt;

${ }^{2}$ Department of Ophthalmology, Beni-Suef University, Beni-Suef, Egypt;

${ }^{3}$ Department of Public Health, Cairo University, Cairo, Egypt; ${ }^{4}$ Public Health and Community Medicine National

Research Center, Cairo, Egypt
Correspondence: Hany El-Mekawey 15 Naser St from Fatma Roshdy St, El Haram, Giza, Cairo I I 222, Egypt Tel +20 I05 206012

$\mathrm{Fax}+20239767329$

Email hany_elmekawey@yahoo.com
Purpose: To evaluate factors behind the delay in diagnosis and treatment among Egyptian patients who present with complicated diabetic retinopathy.

Methods: Observational cross-sectional study of diabetic patients with advanced diabetic retinopathy. Patients were asked to answer a questionnaire to assess the impact of several sociodemographic factors.

Results: A total of 397 patients agreed to take the questionnaire. Diabetic vitreous hemorrhage was the most common ocular complication and was found in 359 patients $(90.4 \%)$. A total of 158 (39.8\%) patients knew that diabetes mellitus can be sight threatening, while $240(60.2 \%)$ were not aware until they developed sight threatening complication. A total of 179 patients (45.1\%) had early retirement because of visual loss related to diabetes mellitus. Multivariate logistic regression has shown that education, internist, contact with other patients, and media were respectively significant in predicting the awareness of patients about the sight-threatening effect of diabetic retinopathy.

Conclusion: Patient education regarding diabetes and diabetic eye disease is essential for early detection and compliance with treatment. Illiteracy has a significant impact on development of sight-threatening diabetic complications. The internist is the first line of prophylaxis. Media has to participate more in patient education.

Keywords: blindness, education, laser photocoagulation, macular edema, vitreous hemorrhage

\section{Introduction}

Diabetes mellitus is an increasing health problem that currently affects more than 150 million people worldwide and is expected to affect more than 200 million people by the year 2025. ${ }^{1}$ Diabetes mellitus is a chronic metabolic multisystem disease. Complications from diabetes can be classified as microvascular or macrovascular. Microvascular complications include system damage as diabetic peripheral neuropathy, renal nephropathy, and diabetic retinopathy. Macrovascular complications include cardiovascular disease and stroke, and peripheral vascular disease, which may lead to diabetic foot, gangrene, and amputation. ${ }^{2}$

Herman et $\mathrm{al}^{3}$ found that diabetic retinopathy accounted for about $42 \%$ of diabetic patients in Egypt; however, the study done by Macky et $\mathrm{al}^{4}$ found the incidence to be $20.5 \%$. This improvement could be attributed to early detection of diabetic patients, with better medical care. ${ }^{3,4}$ The duration of diabetes remains the most significant predictor of visual impairment among people with type II diabetes. 
Visual loss in diabetic patients is often a late symptom of advanced diabetic retinopathy, with serious undesirable consequences affecting the health and vision-related quality of life. ${ }^{5}$ The progression of diabetic retinopathy can have a deleterious effect on patients, both physically and emotionally. Advanced diabetic eye disease can have a significant economic burden on the patient, family members, society, and the health care system. ${ }^{6}$

According to the recommendations of the American Academy of Ophthalmology, the first fundus examination in patients with type I diabetes mellitus should be performed 5 years after diagnosis because retinopathy rarely develops before this period. However, patients with type II diabetes mellitus should be examined immediately when they are diagnosed, because the duration of diabetes is uncertain and some degree of diabetic retinopathy may be present..$^{7-9}$

Several multicenter studies have shown that if laser photocoagulation is initiated at the proper time for treatment of diabetic retinopathy, the probability of blindness is considerably reduced. Hence proper management of diabetic eye disease requires collaboration between an internist and an ophthalmologist. ${ }^{10-13}$ Furthermore, patient education regarding diabetes and diabetic eye disease is essential for compliance with treatment.

The primary objective of this study is to highlight sociodemographic factors responsible for blindness caused by diabetic retinopathy among the Egyptian population.

\section{Materials and methods}

This study was conducted among a sequential sample of 397 diabetic patients with preventable or treatable retinal complications. The study included patients presented to governmental hospitals of Kasr El eini (Cairo University Hospital), Beni-Suef University Hospital, insurance clinics, Agooza and Mabarra Ministry of Health hospitals, and private clinics where the authors work. These patients represented samples from almost all health sectors in Egypt: national health insurance, ministry of health, university teaching hospitals, and the private sector. The study was conducted between February 2008 and March 2010.

Inclusion criteria included patients with diabetic vitreous hemorrhage, tractional retinal detachment involving or threatening the macula, rubeosis irides, macular edema with foveal hard exudates, and cystoid or ischemic maculopathy. Exclusion criteria included all diabetic patients without the abovementioned complications and patients with peripheral stationary tractional retinal detachment.
Table I The questionnaire

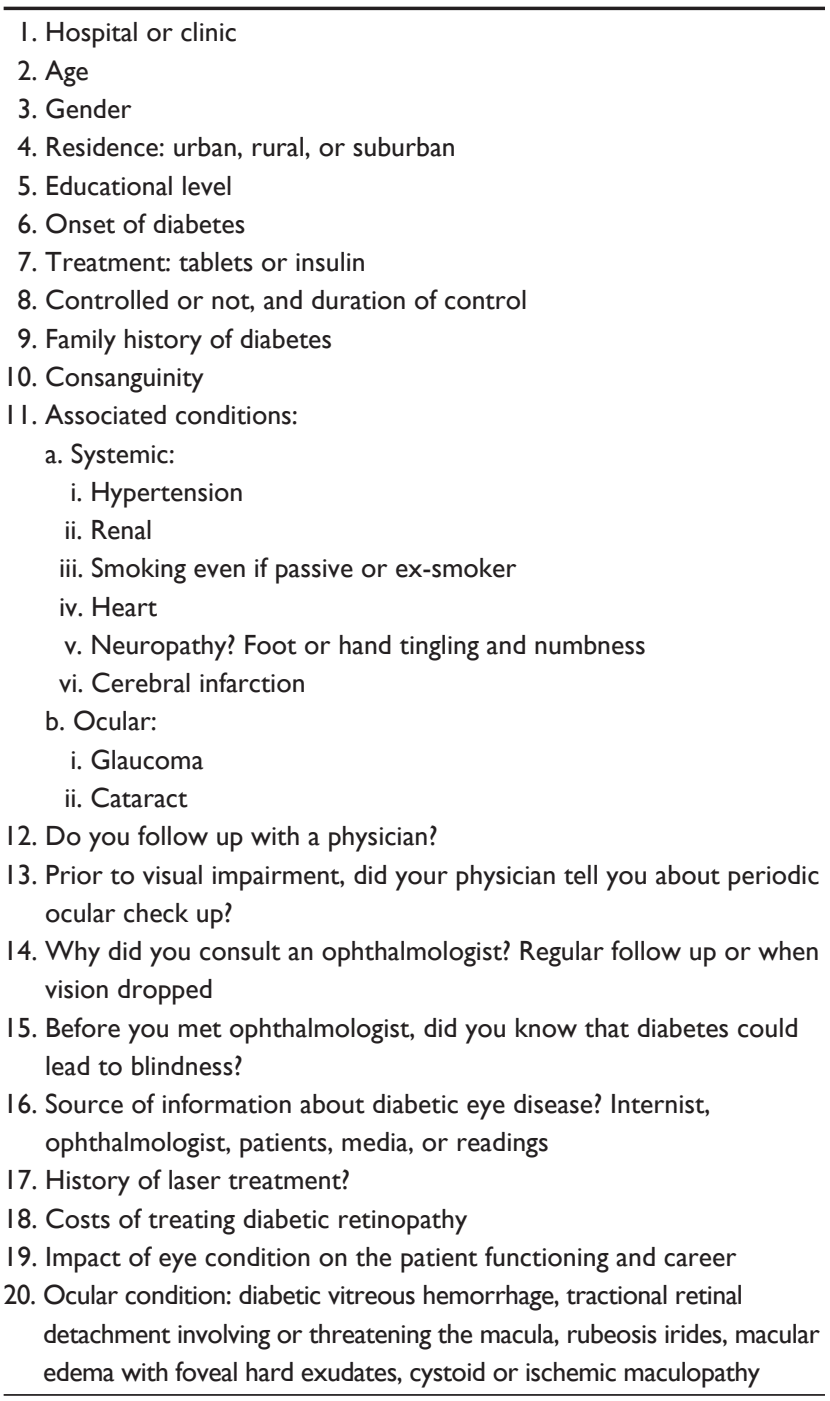

During examination of diabetic patients, those who are legally blind secondary to advanced diabetic retinopathy were asked to answer a questionnaire (Table 1). The data included age, sex, residence, educational level, duration of diabetes, duration of diabetes adjustment, type of therapy, family history of diabetes, consanguinity, smoking, associated systemic disease (eg, hypertension, nephropathy, neuropathy, cerebrovascular, myocardial infarction), associated cataract, and glaucoma. Several questions were used to assess the patient education regarding diabetic eye disease and its impact on their occupational status, laser treatment, and cost of treatment of diabetic retinopathy.

\section{Data analysis}

Data were statistically described in terms of mean \pm standard deviation (SD), frequencies (number of cases) and relative 
frequencies (percentages) when appropriate. Multivariate logistic regression analysis was done to test for the preferential effect of the independent variables of age, sex, residence, education, source of information about diabetic retinopathy, and the awareness of patients about the sight-threatening effect of diabetes mellitus. A probability value ( $P$-value) less than 0.05 was considered statistically significant. All statistical calculations were done using computer programs Microsoft Excel 2003 (Microsoft Corporation, NY) and SPSS (SPSS Inc, Chicago, IL).

\section{Results}

The data were collected from these patients. As shown in Table 2 , the mean age was 56 years ( $\mathrm{SD} \pm 8.56)$. The number of males was 155 (39\%) and females was 242 (61\%). A total of 123 (31\%) reported they smoke, whereas 274 $(69 \%)$ did not.

There were 196 patients (49.4\%) living in urban areas, $144(36.3 \%)$ in rural and $57(14.4 \%)$ living in suburban areas. The mean duration of diabetes mellitus was 16.1 years (SD 6.78). Family history of diabetes mellitus was positive among 320 (80.6\%), whereas 77 patients (19.4\%) had no family history of diabetes mellitus. Consanguinity was positive among 98 patients $(24.7 \%)$.

Table 2 Sociodemographic and clinical data

\begin{tabular}{|c|c|c|}
\hline Sociodemographic data & Mean \pm SD & Patient number (\%) \\
\hline Age, years & $56(8.56)$ & \\
\hline \multicolumn{3}{|l|}{ Sex } \\
\hline Male & 155 (39\%) & \\
\hline Female & $242(61 \%)$ & \\
\hline \multicolumn{3}{|l|}{ Residence } \\
\hline Urban & & $196(49.4 \%)$ \\
\hline Rural & & $144(36.3 \%)$ \\
\hline Suburban & & $57(14.4 \%)$ \\
\hline $\begin{array}{l}\text { Duration of diabetes } \\
\text { mellitus in years }\end{array}$ & I6.I (6.78) & \\
\hline $\begin{array}{l}\text { Family history of } \\
\text { diabetes mellitus }\end{array}$ & & $320(80.6 \%)$ \\
\hline Consanguinity & & $98(24.7 \%)$ \\
\hline \multicolumn{3}{|l|}{ Associated systemic disease } \\
\hline Peripheral neuropathy & & $350(88.2 \%)$ \\
\hline Hypertension & & $237(59.7 \%)$ \\
\hline Cardiovascular disease & & $64(16.1 \%)$ \\
\hline Nephropathy & & $23(5.8 \%)$ \\
\hline $\begin{array}{l}\text { Cerebrovascular } \\
\text { disease (stroke) }\end{array}$ & & $20(5 \%)$ \\
\hline \multicolumn{3}{|l|}{ Associated ocular disease } \\
\hline Cataract & & 164 (4I.3\%) \\
\hline POAG & & $13(3.3 \%)$ \\
\hline Neovascular glaucoma & & $10(2.5 \%)$ \\
\hline
\end{tabular}

Abbreviations: POAG, primary open angle glaucoma; SD, standard deviation.
The patients' levels of education were also recorded. Out of the 397 patients, 140 (35.3\%) were found illiterate, $59(14.9 \%)$ were able to read and write, 161 (40.6\%) had some degree of education ranging from primary to high school diploma, 35 (8.8\%) had a graduate university degree, and only $2(0.5 \%)$ had postgraduate studies.

Diabetic peripheral neuropathy was the most common associated systemic disorder, with tingling and parathesia symptoms recorded in $350(88.2 \%)$ patients. Hypertension ranked second, with 237 (59.7\%) patients. Cardiovascular disease such as myocardial infarction was noted in 64 (16.1\%) patients. Nephropathy was reported among 23 (5.8\%) patients, and $20(5 \%)$ patients had a prior cerebrovascular accident.

The most common cause of blindness was diabetic vitreous hemorrhage affecting 359 patients $(90.4 \%)$. Other causes of blindness were tractional detachment (165 patients, $41.6 \%$ ), cystoid macular edema or foveal hard exudates (114 patients, $28.7 \%$ ), end stage diabetic retinopathy (37 patients, 9.32\%), and central retinal vein occlusion (16 patients, 4\%).

A total of 164 (41.3\%) patients had associated cataract. Glaucoma was reported in 23 patients (5.8\%): $13(3.3 \%)$ patients were noted to have primary open angle glaucoma, while $10(2.5 \%)$ patients had neovascular glaucoma.

A total of $349(87.9 \%)$ patients reported regular follow up with an internist, whereas 48 (12.1\%) did not.

In our structured interview, we assessed patient education, source of information about diabetic retinopathy, and the effectiveness of the doctor-patient relationship.

When questioned about diabetic retinopathy as a cause of blindness, only $158(39.8 \%)$ patients knew that diabetes mellitus can be sight threatening, while 239 (60.2\%) were not aware until they developed sight-threatening complications. Only 118 (29.7\%) were informed by the internist about the necessity of dilated fundus examination. Forty-two patients $(10.6 \%)$ reported that they follow up regularly with an ophthalmologist, whereas $355(89.4 \%)$ reported that they have been to ophthalmologist only because of visual deterioration.

Regarding patient education and source of information about diabetic retinopathy, 139 (35\%) chose their internist, $391(98.5 \%)$ chose their ophthalmologist, 59 (14.9\%) referred to other patients, $34(8.6 \%)$ chose media, while $14(3.5 \%)$ acquired their knowledge on diabetic retinopathy through reading printed articles.

Multivariate logistic regression in Table 3 showed that age, sex, residence, patient knowledge acquired through 
Table 3 The preferential effect of independent variables (age, sex, residence, education, role of internist, ophthalmologist, patient, and media in predicting the awareness of patients about the sightthreatening effect of diabetes mellitus

\begin{tabular}{lllll}
\hline $\begin{array}{lllll}\text { Independent } \\
\text { variable }\end{array}$ & $\begin{array}{l}\text { Odds } \\
\text { ratio }\end{array}$ & \multicolumn{2}{l}{$\begin{array}{l}\text { 95\% Cl for } \\
\text { odds ratio }\end{array}$} & P-value \\
\cline { 2 - 4 } & & Lower & Upper & \\
\hline Age & 1.013 & 0.965 & 1.064 & 0.603 \\
Sex & 2.051 & 0.790 & 5.326 & 0.140 \\
Residence & 1.131 & 0.628 & 2.038 & 0.682 \\
Education level & 1.473 & 1.092 & 1.987 & 0.011 \\
Internist & 156.058 & 63.318 & 384.632 & 0.000 \\
Ophthalmologist & 0.573 & 0.021 & 15.947 & 0.743 \\
Patient & 8.508 & 2.988 & 24.226 & 0.000 \\
Media & 29.962 & 5.567 & 161.257 & 0.000 \\
Reading & 0.69 & 0.001 & 11.9 & 0.998 \\
\hline
\end{tabular}

Abbreviation: $\mathrm{Cl}$, confidence interval.

ophthalmologist, and reading printed articles were found insignificant, while education level (odds ratio [OR] 1.47, confidence interval $[\mathrm{CI}] 1.092-1.99, P=0.01)$, internist (OR 156.1, CI 63.31-384.63, $P<0.001$ ), contact with other patients (OR 8.51; CI 2.99-24.23; $P<0.001$ ), and media (OR 29.96; CI 5.57-161.26; $P<0.001$ ) had a significant impact on awareness of patients about diabetic retinopathy.

A total of 130 patients $(32.7 \%)$ received laser treatment for diabetic retinopathy at the time of the survey.

Regarding the impact of diabetic eye disease on work, 179 (45.1\%) took early retirement because of visual loss related to diabetes mellitus.

A total of 291 (73.3\%) patients partially paid for their diabetic retinopathy treatment. The cost varied from 20 to 8000 Egyptian pounds with a mean of 630.5 Egyptian pounds. The government supported 314 (79.1\%) patients. The cost varied from 300 to 8200 Egyptian pounds with a mean of 2523.41 Egyptian pounds paid by Ministry of Health and National Health Insurance. The total economic burden for treating diabetic eye disease in these patients was 975,840 Egyptian pounds: the government paid $792,350(81.2 \%)$, while patients paid 183,490 $(18.8 \%)$.

\section{Discussion}

The Wisconsin Epidemiological Study of Diabetic Retinopathy (WESDR) concluded that $3.6 \%$ of those diagnosed with type I and 1.6\% of those diagnosed with type II diabetes mellitus were legally considered blind. For type I diabetes mellitus, blindness was mostly ( $86 \%$ ) due to diabetic retinopathy. For type II, blindness was related to retinopathy in $33 \%$ of the cases. ${ }^{14}$

The annual incidence of retinopathy requiring ophthalmological follow up or treatment has been reported to average $1.5 \%$ after 1 year. Between $6 \%$ and $9 \%$ of patients with proliferative retinopathy or severe nonproliferative disease would become blind each year. ${ }^{15}$

In our study, living in urban areas was not an advantage; as 196 (49.4\%) of the patients included in this study developed advanced diabetic eye disease.

Our results show that patient awareness about diabetic retinopathy was low, since only 158 (39.8\%) knew about the possible deleterious effect of diabetes on eyesight. This may be related to low patient education, as 140 $(35.2 \%)$ were illiterate. Illiteracy may contribute to noncompliance and inefficient doctor-patient education. Low income may discourage patients from seeking medical advice.

However, the result for patient awareness in the present study is higher than in other Egyptian and Indian studies which demonstrated that $14.7 \%$ and $18 \%$ of patients respectively were aware of the hazards of diabetes mellitus for the eyes. ${ }^{4,16}$ The difference may be attributed to better distribution of the patient sample through all socioeconomic classes of the Egyptian population and not only the low, illiterate one.

Effective methods to deliver patient education and teach self-management skills that result in longer-term improvements to health are needed. All primary care organizations, as suggested by the Diabetes National Service Framework and the National Institute for Clinical Excellence, must offer structured educational programs to people with diabetes in order to improve glycemic control, reduce requirement for diabetes medication, improve early detection of diabetic complications, and treatment satisfaction. ${ }^{17-22}$

Multivariate logistic regression showed the importance of edication in predicting patients' awareness about diabetic retinopathy (Odds ratio, 1.47, CI 1.092-1.99, $P=0.01)$. With regard to the source of information on diabetic retinopathy, our result shows that the sources were multiple and patients' level of knowledge varied. Almost one-third of the patients acquired their knowledge through their internist, while most $(391,98.5 \%)$ chose their ophthalmologist after their visual loss. Multivariate logistic regression showed the role of the internist to be of utmost importance in predicting the awareness of patients about 
diabetic retinopathy with OR 156.1, CI 63.31-384.63, $P<0.001$. Patients present late to the ophthalmologist, and the role of the internist in the prophylaxis, patient education, and early detection of diabetic retinopathy is crucial.

Although 59 (14.9\%) patients referred to other patients and $34(8.6 \%)$ chose media as a source of information about diabetic eye disease, both sources were found to be statistically significant in promoting patients' awareness about the sight-threatening effect of diabetes mellitus (other patients OR 8.5, CI 2.99-24.23, $P<0.001$ and media OR 29.96; CI 5.57-161.26, $P<0.001$, respectively).

Laser photocoagulation represents the mainstay of prophylaxis against complications of diabetic retinopathy. ${ }^{11}$ In our study, only $32.7 \%$ of patients received laser treatment at the time of the survey.

This study showed that the Egyptian government carried most of the direct costs of treating diabetic retinopathy. The government expenditure constituted $81.2 \%$, while the patient's economic burden was only $18.8 \%$. The indirect cost could not be calculated. The main bulk of the indirect cost is lost productivity due to temporary work disability, absenteeism, early retirement, rehabilitation, and medication fee. ${ }^{22}$ In this study, $45.1 \%$ had early retirement because of visual loss related to diabetes mellitus.

The strength of our study lies in the relatively large sample size of patients and the structured interview, which included much sociodemographic data besides the clinical examination. This descriptive study has included data from several referral centers representing the four main health organizations in Egypt.

The following limitations have to be realized: firstly, the self-reported nature of the questionnaire is subject to informant bias; and secondly, the selection bias, which is due to exclusion of diabetic patients with normal fundus.

In conclusion, this descriptive study found that illiteracy contributes to noncompliance and late presentation. The role of the internist and media in improving the awareness of patients about diabetic retinopathy is of utmost importance.

A continuous medical education program with implementation of evidence-based practices and screening programs for early detection of diabetic retinopathy are essential to improve the standard of care.

\section{Acknowledgment}

The authors would like to thank Dr Amr Salah, the head of the Ophthalmology Department of Cairo University, for his guidance; and Dr Hany Hamed El Defrawy, Dr Mahmoud Gamal, and Dr Salah Ali Makhlof for their help in data collections.

\section{Disclosure}

The authors report no conflicts of interest in this work. The authors alone are responsible for the content and writing of the paper.

\section{References}

1. World Health Organization (WHO). The World Health Report: conquering suffering, enriching humanity. Geneva: WHO; 1997.

2. Deshpande AD, Harris-Hayes M, Schootman M. Epidemiology of diabetes and diabetes related complications. Phys Ther. 2008;88: 1254-1264.

3. Herman WH, Aubert RE, Engelgau MM, et al. Diabetes mellitus in Egypt: glycaemic control and microvascular and neuropathic complications. Diabet Med. 1998;15:1045-1051.

4. Macky TA, Khater N, Al-Zamil MA, El Fishawy H, Soliman MM Epidemiology of diabetic retinopathy in Egypt: a hospital-based study. Ophthalmic Res. 2011;45:73-78.

5. World Health Organization. Prevention of blindness and visual impairment Available from: http://www.who.int/blindness/causes/en/index. html Accessed July 5, 2011.

6. Coyne KS, Margolis MK, Kennedy-Martin T, et al. The impact of diabetic retinopathy: perspectives from patient focus groups. Fam Pract. 2004;21:447-453.

7. American Academy of Ophthalmology. Preferred Practice Pattern: Diabetic Retinopathy. San Francisco: American Academy of Ophthalmology; 1993.

8. Klien R, Klien BEK, Moss SE, Davis MD, DeMets DL. The Wisconsin Epidemiologic Study of Diabetic Retinopathy II: prevalence and risk of diabetic retinopathy when age of diagnosis is less than 30 years. Arch Ophthalmol. 1984;103:520-526.

9. Klien R, Klien BEK, Moss SE, Davis MD, DeMets DL. The Wisconsin Epidemiologic Study of Diabetic Retinopathy IX: four year incidence and progression of diabetic retinopathy when age of diagnosis is less than 30 years. Arch Ophthalmol. 1989;107:237-243.

10. The Diabetic Retinopathy Study Research Group. Photocoagulation treatment of proliferative diabetic retinopathy. Clinical application of Diabetic Retinopathy Study (DRS) findings, DRS report no 8. Ophthalmology. 1981;88:583-600.

11. The Diabetic Retinopathy Study Research Group. Four risk factors for severe visual loss in diabetic retinopathy. The third report from the Diabetic Retinopathy Study. Arch Ophthalmol. 1979;97:654-655.

12. Early Treatment Diabetic Retinopathy Study Research Group. Photocoagulation for diabetic macular edema. Early Treatment Diabetic Retinopathy Study report number 1. Arch Ophthalmolol. 1985;103: 1796-1806.

13. Early treatment Diabetic Retinopathy Study Research Group. Early photocoagulation for diabetic retinopathy. ETDRS report no, 9. Ophthalmology. 1991;98:766-785.

14. Klein R, Klein BEK, Moss SE. The Wisconsin Epidemiological Study of Diabetic Retinopathy: a review. Diabetes Metab Rev. 1989;5(7): 559-570.

15. Amos AF, McCarty DJ, Zimmet P. The rising global burden of diabetes and its complications: estimates and projections to the year 2010. Diabetic Med. 1997;14(Suppl 5):S1-S85.

16. Deepa M, Deepa R, Shanthirani CS, et al. Awareness and knowledge of diabetes in Chennai - the Chennai Urban Rural Epidemiology Study [CURES-9]. J Assoc Physicians India. 2005;53:283-287. 
17. Department of Health (DOH). National Service Framework for Diabetes: standards. London: DOH; 2001.

18. Department of Health (DOH). National Service Framework for Diabetes: delivery strategy 29895. London: DOH; 2003.

19. National Institute for Clinical Excellence (NICE). Guidance on the Use of Patient-Education Models for Diabetes. Technology Appraisal 60. London: NICE; 2003.

20. Department of Health (DOH). The Performance and Planning Framework for 2003-2006. Improvement expansion and reform: the next three years. London: DOH; 2003.
21. Deakin TA, Cade JE, Williams R, Greenwood DC. Structured patient education: the Diabetes X-PERT Programme makes a difference. Diabetic Med. 2006;23(9):944-954.

22. Smith A. The economic impact of ophthalmic services for persons with diabetes in the Canadian province of Nova Scotia. Ophthalmic Epidemiol. 2001;8(1):13-25.
Clinical Ophthalmology

\section{Publish your work in this journal}

Clinical Ophthalmology is an international, peer-reviewed journal covering all subspecialties within ophthalmology. Key topics include: Optometry; Visual science; Pharmacology and drug therapy in eye diseases; Basic Sciences; Primary and Secondary eye care; Patient Safety and Quality of Care Improvements. This journal is indexed on

\footnotetext{
Submit your manuscript here: http://www.dovepress.com/clinical-ophthalmology-journal
}

\section{Dovepress}

PubMed Central and CAS, and is the official journal of The Society of Clinical Ophthalmology (SCO). The manuscript management system is completely online and includes a very quick and fair peer-review system, which is all easy to use. Visit http://www.dovepress.com/ testimonials.php to read real quotes from published authors. 